\title{
La Escuela Taller de la Chiquitania (Bolivia): los talleres productivos como posible germen de empresas de economía social
}

\author{
Luis Díez Ácimas \\ Funcionario de la Administración General del Estado \\ Experto en Derecho de las Cooperativas
}

Recibido: 18-01-2019

Aceptado: 28-02-2019

Sumario: I. Aproximación a la realidad económica de Bolivia. 1.1 Datos generales sobre la situación económica de Bolivia. 1.2. Economía social y economía solidaria en Bolivia. 1.2.1. Figuras de economía social. 1.2.2. Figuras de economía solidaria. II. La región de la Chiquitania. 2.1. Localización. 2.2. Economía. 2.3. Identidad cultural. III. La cooperación internacional del Ministerio de Trabajo, Migraciones y Seguridad Social. IV. La Escuela Taller de la Chiquitania. 4.1. Análisis de la situación de la ETCH. 4.2. Actividades económicas que se pueden realizar en los talleres productivos de la ETCH e ideas de posibles emprendimientos de economía social. 4.2.1. Gastronomía. 4.2.2. Carpintería. 4.2.3. Construcción. 4.2.4. Actividades de carácter general. 4.3. Vías de comercialización de los productos. $\checkmark$. De los talleres productivos de la ETCH a microempresas de economía social.

Resumen: La Escuela Taller de la Chiquitania (ETCH) nace en 2007, con el objetivo de contribuir a la rehabilitación integral del Conjunto Misional de San José de Chiquitos. Posteriormente, ha intervenido en los otros cinco conjuntos misionales nominados Patrimonio de la Humanidad ubicados en la Chiquitania. En 2017, se inicia un nuevo ciclo en la ETCH, creando dos talleres productivos, con el objetivo de buscar una mayor sostenibilidad técnica, económica e institucional del proyecto.

En el programa de asistencias técnicas de cooperación internacional del Ministerio de Trabajo, Migraciones y Seguridad Social de España, correspondiente a 2018, se incluye una que tiene como destinataria a la ETCH con el objetivo de incluir la perspectiva de la economía social en las actividades de la escuela; y, especialmente, en los talleres productivos.

En este artículo, se reflejan las actuaciones de la asistencia técnica llevada a cabo, después de conocer la ETCH y la realidad socioeconómica de la Chiquitania.

Palabras clave: Formación. Empleo. Cooperación. Emprendimiento. Economía Social. 
Abstract: Chiquitania's Worshop School (ETCH) is created with the aim of contributing to the rehabilitation of the missionary group of San José de Chiquitos. Subsequently the ETCH has intervened in other six missionary groups nominees World Heritage Sites and locates in the Chiquitania. In 2017, a new cycle is started in with the creation of two productive workshops in order to find a more technical, institutional and economic sustainability of the project.

The technical assistance programme for international cooperation of the Ministry of Labour, Migration and Social Security of 2018 includes one technical assistance for the ETCH, in order to include the perspective of the social economy in the activities of the school and especially in the productive workshops.

This article reflects the actions of technical assistance carried out, once the school and the socio-economic reality of the area has been known.

Keywords: Training. Employment. Cooperation. Entrepreneurship. Social Economy. 


\section{Aproximación a la realidad económica de Bolivia}

El Estado Plurinacional de Bolivia está situado en la región centrooccidental de América del Sur y tiene una superficie de casi 1.100.000 $\mathrm{km}^{2}$, ocupando el 28. ${ }^{\circ}$ lugar en el mundo por su extensión. Limita al norte y al oriente con Brasil, al sur con Paraguay y Argentina, y al occidente con Chile y Perú, es un estado sin litoral y mantiene una reclamación territorial a Chile por una salida soberana al océano Pacífico, la cual no tuvo resultados positivos en la Corte Internacional de Justicia de La Haya. Cuenta con una población aproximada de 11.400.000 habitantes (puesto 87..$^{\circ}$.

\subsection{Datos generales sobre la situación económica de Bolivia}

Su PIB (PPA; paridad del poder adquisitivo) le coloca en el lugar 89. ${ }^{\circ}$ del mundo. El PIB nominal le coloca en el puesto $95 .^{\circ}$. Si tomamos como referencia el IDH (Índice de Desarrollo Humano) elaborado por el Programa de Naciones Unidas para el Desarrollo (PNUD), se coloca en el puesto $118 .^{\circ}$, de un total de 187 países analizados, calificado como nivel de desarrollo medio, por el propio organismo ${ }^{1}$.

Bolivia es un país en vías de desarrollo, de ingreso medio y durante más de una década ha liderado el crecimiento económico de la región sudamericana. Su economía tiene como base principal la extracción y la exportación de sus recursos naturales, principalmente mineros y gasísticos. También, tiene un importante desarrollo la actividad de generación de energía eléctrica.

En la minería, Bolivia destaca en la producción de estaño, antimonio, plomo, zinc y plata.

En el sector agroindustrial se ha producido un importante desarrollo en los últimos tiempos, debido a la tecnificación y la optimización de la producción agraria. Se cultiva, entre otros, soja, caña de azúcar, girasol, arroz, papa, cebada y productos muy demandados para la exportación como quinoa, cacao y café. En ganadería, destaca la cría de ganado bovino en el oriente, mientras que en occidente, la cría de camélidos, como la alpaca, es importante para su utilización por la industria textil.

1 Índices e indicadores de desarrollo humano. Actualización estadística de 2018. Se puede consultar en http://hdr.undp.org/sites/default/files/2018_human_development_ statistical_update.pdf. 
El turismo avanza. Ha crecido en los últimos años. Bolivia roza el millón de visitantes anuales, favorecido por los contrastes, dentro del mismo país, entre las altas montañas de los Andes y las selvas tropicales amazónicas. Podemos afirmar que ya son cientos de miles los bolivianos que trabajan en empleos directa o indirectamente relacionados con el turismo: hoteles, hosterías, restaurantes, centros de diversión nocturnos, transportes de pasajeros, aerolíneas, elaboración y comercio de suvenires,...

Aunque la crisis mundial afectó de forma importante a la economía de América Latina; Bolivia se mantiene como un país atractivo para la inversión pública y privada. Los sectores que acogen más inversiones son la construcción, la agroindustria, el turismo y el comercio.

El nivel de desempleo es bajo (4,4\%); pero, resulta preocupante el alto nivel de informalidad en los empleos, alcanzando, según algunas fuentes, el $70 \%$ del total.

El microcrédito tiene gran relevancia en Bolivia. Se considera que es uno de los países del mundo que lidera en la oferta de este tipo de producto financiero. Eso se justifica con la cantidad de microempresas y trabajadores por cuenta propia que se mueven en el mercado informal como decíamos anteriormente; y, que recurren a fórmulas modestas de inversión.

La economía boliviana, según el informe de Milenio² sobre esta, ha demostrado su extrema vulnerabilidad a potenciales shocks externos de rebaja de los precios de exportación, especialmente de hidrocarburos. En efecto, la caída de precios observada en 2014, 2015 y 2016, ha puesto en evidencia la fragilidad de los equilibrios macroeconómicos presentados hasta 2014. Esta caída viene acompañada de déficits externos y fiscales significativos, que, a su vez, se traducen en mayores niveles de endeudamiento y en pérdida de reservas internacionales.

Los shocks externos también han reducido el ritmo de crecimiento económico en 2017 y 2018, prosiguiendo la tendencia de desaceleración manifestada a partir de 2015. Si en 2014 el PIB creció en 5.4\%, en 2017 este crecimiento se redujo a 4.2\%. En el primer trimestre de 2018, la tasa de crecimiento llegó a 4.4\%.

En ese escenario, sigue afirmando el informe Milenio, es verdad que la recuperación de los precios internacionales, observada durante los dos últimos años, ha devenido un alivio parcial de los desequilibrios macroeconómicos, pero sin llegar a revertirlos. Como resultado, la eco-

2 EVIA, J.L, JEMIO, L.C. «Informe de Milenio sobre la economía de Bolivia». Fundación Milenio. 2018, número 40. 
nomía boliviana exhibe una situación incierta, caracterizada por un elevado déficit externo y fiscal, así como también por la desaceleración del crecimiento económico y la pérdida de competitividad cambiaria.

\subsection{Economía social y economía solidaria en Bolivia}

El nuevo modelo económico boliviano, aprobado en la Constitución Política del Estado de 2009, es plural y orientada a la mejora de la calidad de vida y el vivir bien. La economía plural está compuesta por las formas de organización económica comunitaria, estatal, privada y social cooperativa. Se aclara que la economía social y comunitaria complementará el interés individual con el «vivir bien» colectivo (art. 306). Es evidente, en opinión de Coraggio ${ }^{3}$, que este marco constitucional prioriza las formas de trabajo autogestionado que componen la economía popular.

Respecto a la economía social en Bolivia, hay que empezar diciendo que esta noción, como recuerda Mercado ${ }^{4}$, no ha tenido mucho éxito. Aunque su uso en los discursos políticos está muy extendido, su tratamiento académico es casi inexistente. Lo que evidentemente ha logrado cierto posicionamiento en el debate ideológico es la noción de solidaridad o "economía solidaria», asociada ésta a la forma tradicional de organizar el proceso productivo que habría estado presente antes de la colonia y que hoy se reflejaría en la producción del campesinado de occidente y en los cinturones de inmigrantes asentados en las ciudades capitales de departamento.

\subsubsection{FigURAS DE ECONOMÍA SOCIAL}

En el lado más tradicional de las figuras de economía social, se encuentra la cooperativa, que es definida por el artículo 4 la Ley General de Cooperativas de Bolivia ${ }^{5}$ como «una asociación sin fines de lucro, de

3 CORAGGIO, J.L. «La presencia de la economía social y solidaria y su institucionalización en América Latina», Documento ocasional 7. Potencial y límites de la economía social y solidaria. 2014. United Nations Research Institute for Social Development.

4 MERCADO, A.F. "Un acercamiento a la realidad (Bolivia). En «La economía social en Iberoamérica, vol. 2, Un acercamiento a la realidad», Coordinada por PÉREZ URALDE, J,M, y RODRIGÁN RUBIO, M. Fundación Iberoamericana de la Economía Social. 2002, págs. 13-41.

5 Ley número 356. Ley de 11 de abril de 2013. Configura un modelo de sociedad cooperativa perfectamente homologable con el concepto elaborado por la Alianza Cooperativa Internacional $(\mathrm{ACl})$. 
personas naturales y/o jurídicas que se asocian voluntariamente, constituyendo cooperativas, fundadas en el trabajo solidario y de cooperación, para satisfacer sus necesidades productivas y de servicios, con estructura y funcionamiento autónomo y democrático».

El análisis que hace Mercado del sector cooperativo no arroja un resultado muy positivo. Afirma que las cooperativas de educación no son otra cosa que empresas privadas que formalmente aparecen como cooperativas con el objeto de eludir el pago de ciertos impuestos y poder realizar ciertos cobros extraordinarios a los padres de los estudiantes sin tener que dar explicaciones a las autoridades de educación. Dice que las cooperativas de transporte son organizaciones de propietarios de vehículos de transporte público cuyo único objetivo es mantener un monopolio de ciertas áreas o zonas de trabajo. Al referirse a las cooperativas agropecuarias señala que no tienen ninguna importancia económica ni social; en general; son organizaciones que, bajo el amparo de formas cooperativas, solamente buscan tener un control político de sus afiliados. Continúa indicando este autor que las cooperativas de servicios básicos son, probablemente, las que cumplen una verdadera función de cooperativas; sin embargo, su representación es muy reducida. Las cooperativas de electrificación, repartidas por todo el país, son básicamente organizaciones de las áreas rurales para el manejo de un pequeño sistema de generación eléctrica.

Las cooperativas mineras, por su parte, han asumido una creciente importancia, tanto en volumen de producción como en absorción de mano de obra. Actualmente ocupan a un 70 por ciento de la fuerza laboral del sector. Pero, destaca este autor que del total de la ocupación en las cooperativas, solamente entre un 20 y un 30 por ciento son cooperativistas, mientras que el resto son trabajadores asalariados.

La gran mayoría de las cooperativas constituyen, en opinión de Mercado, unidades productivas de subsistencia ya que carecen de capacidad económica, técnica y empresarial, y sólo algunas cooperativas auríferas han tenido acceso a financiación. El tamaño de las cooperativas varía, va desde unos pocos trabajadores hasta más de mil.

La relevancia que se concede en este artículo a las cooperativas de ahorro y crédito en Bolivia se limita a considerar que actúan como un sistema complementario al sistema bancario.

El otro pilar tradicional de la economía social es el mutualismo. Un sistema solidario de servicios mutuos, fundado en la asociación voluntaria de personas que se unen con objetivos comunes de ayuda recíproca. En el aspecto económico, se sustenta integrando un patrimonio del cual nadie es propietario en forma individual. Este patrimonio pertenece al conjunto total y orgánico de los asociados. En general, puede afirmarse 
que la asociación mutual es una organización creada por personas para recibir determinados servicios cuya adquisición en forma individual les resultaría casi imposible.

En términos formales, son personas jurídicas de derecho privado, sin ánimo de lucro, constituidas democráticamente por personas naturales, inspiradas en la solidaridad, con el objeto de brindarse ayuda recíproca frente a riesgos eventuales y satisfacer sus necesidades mediante la prestación de servicios de seguridad social.

Los activos y las carteras de crédito de las mutuales de ahorro y préstamo que operan en el país, según los datos que aporta Mercado, representan una parte relevante del sistema de intermediación financiera.

\subsubsection{FIGURAS DE ECONOMÍA SOLIDARIA}

Como decíamos anteriormente, el concepto de economía solidaria está más extendido en Bolivia. Este país se caracteriza, según F. Wanderley ${ }^{6}$, por disponer de sólidos tejidos comunitarios y asociativos con formas plurales de organización social, política y económica. Una de estas formas es el gobierno comunal en el área rural, en el que campesinos e indígenas regulan sus relaciones sociales en las comunidades territoriales e interactúan colectivamente con el estado a nivel municipal, departamental y nacional.

Además de la afiliación a gobiernos comunales, los indígenas, campesinos y trabajadores en el área rural y urbana están afiliados a organizaciones económicas como gremios, cooperativas, asociaciones, comunidades agrarias con base en iniciativas de producción familiar.

Si nos centramos en las últimas décadas, según esta autora, vemos que, a partir de 1980, emerge una nueva identidad colectiva nacional indígena. Estas organizaciones se reconstruyen con base en la recuperación de la memoria y prácticas indígenas y originarias en sustitución de los referentes clasistas que habían dominado las movilizaciones en décadas anteriores. Este proceso se vio apoyado en la recuperación documental y académica de las prácticas e instituciones de las comunidades indígenas y su amplia difusión a través de centros de investigación y de radios comunitarias en idiomas autóctonos.

Durante los años noventa, en el marco de las políticas de ajustes estructurales, privatizaciones, de retroceso del frágil estado benefac-

6 WANDERLEY, F. «La economía solidaria y comunitaria en Bolivia». Revista de la Academia. Volumen 21. Otoño de 2016, págs. 57-75. 
tor y precarización del empleo, se multiplicaron emprendimientos e iniciativas económicas autogestionadas por los propios trabajadores en el área rural y urbana. El resultado de este proceso fue la expansión del tejido económico formado por organizaciones al margen de las tradicionales relaciones obrero - patronales como, por ejemplo, las organizaciones económicas campesinas, que reúnen a los miembros de comunidades rurales, con actividades económicas similares; $y$, dispuestos a asociarse para promoverlas. Sus objetivos eran el fomento de espacios de comercialización directa, sin intermediación (tiendas de barrios, ferias locales, regionales y nacionales), así como la apertura de mercados y mejora de las condiciones de venta a grandes comercializadoras. El sentido de lo comunitario está referido principalmente a la proximidad territorial de circuitos cortos de intercambios.

Toda esta energía social, sigue afirmando Wanderley, ganó un nuevo impulso político a partir del año 2000, cuando las organizaciones sociales se movilizaron por la defensa de recursos territoriales de gestión comunitaria o estatal como la tierra, el agua y los hidrocarburos.

Por último, nos referiremos, siguiendo a Hillenkamp ${ }^{7}$, al caso de las organizaciones volcadas específicamente hacia el mundo rural en el que el objetivo de acción colectiva se formula generalmente en términos de creación o reforzamiento de actividades generadoras de ingresos, sean estas artesanales o agrícolas. La creación de fuentes alternativas de trabajo o de actividades productivas o generadoras de ingresos se basa en una estrategia colectiva. Los productores se agrupan y definen una producción común; frecuentemente estandarizan sus productos; a veces, definen una oferta de productos diferentes pero complementarios. Invierten en equipos y fondos rotatorios, muchas veces cofinanciados por la cooperación internacional. Comercializan parte o la totalidad de su producción «como grupo». Gracias a una mayor capacidad de producción, más regular y de calidad más homogénea, pueden acceder colectivamente a suministrar, a la cadena de comercialización, pedidos más exigentes. Obtienen, entonces, una remuneración más alta o, al menos, más regular. La importancia de la etapa de comercialización explica que ciertas organizaciones enfaticen, en la formulación de su objetivo, la importancia de la mejora de las ventas, aunque esto no signifique que su modo de acción difiera significativamente del de otras organizaciones.

7 HILLENKAMP, I. «La economía solidaria en Bolivia. Entre mercado y democracia». (C) cides-umsa/ird.2014. 


\section{La región de la Chiquitania}

\subsection{Localización}

La Chiquitania se ubica en el occidente de Bolivia, en el departamento de Santa Cruz. Abarca aproximadamente $220.000 \mathrm{~km}^{2}$ y representa el $56 \%$ del territorio del departamento de Santa Cruz y el $19 \%$ del territorio boliviano. Tiene una población estimada de alrededor de 225.000 habitantes, lo que nos ofrece una densidad de población muy baja, próxima a 1 habitante por $\mathrm{km}^{2}$. Es una extensa llanura ubicada entre El Gran Chaco y la Amazonía.

Esta región, en palabras de Coimbra ${ }^{8}$, cumple un rol protagonista y estratégico en la integración nacional e internacional pues es el paso de los denominados «corredores de exportación» entre los océanos Pacífico y Atlántico del continente sudamericano.

La Chiquitania está conformada por catorce unidades territoriales o municipios y con el propósito de aunar esfuerzos y sumar voluntades y recursos, se ha creado la Mancomunidad de Municipios Chiquitanos, una entidad que ofrece la posibilidad de propiciar la visión de un territorio integrado, con un destino común, basado en sus recursos, su capacidad productiva y sus comunes valores culturales y simbólicos.

\subsection{Economía}

La situación actual de la economía chiquitana, explica Coimbra, refleja un desarrollo casi exclusivamente relacionado con la explotación de sus recursos naturales y culturales. Se realizan modestas inversiones que no generan un gran valor agregado ni excesiva competitividad.

Los principales sectores económicos en la Chiquitania son la agricultura (soja, caña de azúcar, arroz, mandioca y frutas tropicales), la ganadería extensiva de vacuno y la producción forestal (aunque este sector ha sufrido un grave deterioro últimamente). Se observa el carácter emergente de los sectores del turismo y servicios.

El subsuelo de la Chiquitania parece excepcionalmente rico en hidrocarburos y gas natural, así como en yacimientos de hierro, lo que supone una clara opción de crecimiento.

8 COIMBRA, G. «Desarrollo humano sostenible en las misiones jesuíticas de Chiquitos, Bolivia: el caso del municipio de Concepción». Disponible en:

http://bioculturaldiversityandterritory.org/documenti25_300000176_08_desarrollohumanosostenible.pdf. 
Del recorrido por las localidades que acogen los diferentes conjuntos misionales y de las informaciones recabadas del personal de la ETCH y del Plan Misiones, así como de responsables de patrimonio artístico y turismo de algunos municipios y de las visitas a talleres productivos vinculados a diversas instituciones (especialmente, a la Iglesia Católica) y actividad de elaboración de productos artesanos y centros de comercialización de los mismos, así como de las visitas a los centros de gastronomía y hotelería, cuyos servicios se han utilizado en el recorrido, se sacan las siguientes conclusiones, que confirman lo afirmado anteriormente:

- La agricultura y ganadería siguen siendo actividades muy relevantes en la región. Aunque en algunos casos, sea limitada a la actividad de subsistencia.

- Se nota un auge de los servicios de gastronomía y hotelería.

- Tienen mayor presencia algunos servicios, tales como el comercio (la cercanía de algunas localidades con Brasil facilita esta actividad) y el transporte.

- Se puede incidir más en aspectos turísticos, no solo desde el punto de vista de la hostelería, sino también, en otros servicios como guías o acompañantes a las visitas turísticas; $y$, sobre todo, a actividades tendentes a la conservación del patrimonio históricoartístico. Esta es una actividad necesaria para que los conjuntos misionales y otros monumentos de la región no sufran un deterioro de tal magnitud que después haga muy dificultosa su recuperación. Se considera vital la realización de actividades constantes de mantenimiento y pequeña reparación, al margen de las grandes actuaciones de restauración a realizar cuando sea preciso.

Respecto a la situación de la economía social, se puede repetir lo dicho respecto a Bolivia en general. Hay presencia de las cooperativas de crédito, transportes y suministro de servicios. Se nota, en cambio, la ausencia de pequeñas cooperativas de producción.

\subsection{Identidad cultural}

La identidad cultural de este amplio territorio, sigue afirmando Coimbra, está ligada a su origen étnico y al proceso histórico que en él se ha desarrollado. El mismo proceso que ha marcado las transformaciones sociales, culturales y políticas.

La conquista española asignó territorios a diferentes órdenes religiosas para efectuar misiones evangelizadoras, y lo que hoy es Bolivia 
(Moxos y Chiquitos) le correspondió a la orden de los jesuitas en el período comprendido entre 1691 y 1767. Si bien este período es relativamente corto, es el que más ha marcado la vida, costumbres e idiosincrasia de los chiquitanos.

Los misioneros de la Compañía de Jesús tuvieron que recorrer un largo camino para llegar al Nuevo Mundo. A su llegada a territorio boliviano, se dedicaron a la tarea de concentrar a las tribus nómadas en comunidades denominadas «reducciones», para instruir a los indígenas sobre la vida civil, religiosa y musical.

La Provincia de Chiquitos fue el primer escenario de este encuentro entre las culturas nativa y española. En este territorio se fundó Santa Cruz de la Sierra en 1561, que se convirtió en la capital de la Gobernación del mismo nombre creada un año antes. A principios del siglo XVII la capital fue trasladada y la Provincia de Chiquitos prácticamente abandonada. Al igual que en otros lugares de América, los jesuitas establecieron en la Chiquitania reducciones de población exclusivamente indígena que trabajaba bajo la tutela de dos religiosos; uno encargado de lo espiritual, es decir, del proceso evangelizador; y, el otro, de lo material, fundamentalmente de la enseñanza de las artes y oficios europeos y de la administración.

En poco tiempo, afirma Coimbra, los chiquitanos se convirtieron en magníficos artesanos (carpinteros, alfareros, tejedores, talabarteros, pintores, escultores, etc.); pero, sobre todo, destacaron en el campo musical. Los misioneros utilizaron la música como vehículo de evangelización y los chiquitanos se convirtieron en excepcionales músicos, no sólo cantores y ejecutantes, sino también compositores.

Los jesuitas, para la conformación de las reducciones, recurrieron a sistemas usados en otros países latinoamericanos por los franciscanos y dominicos, en los cuales los lugareños eran súbditos de la Corona, pero dueños de la tierra.

Las reducciones se implantaron siguiendo el urbanismo jesuita. Incorporaba las ideas del espíritu barroco, buscando la ciudad de Dios, estableciéndose en lugares sanos, elevados, de fácil acceso, defendibles y provistos de agua. La plaza constituía el elemento ordenador. Era rectangular, decorada en el centro con una cruz rodeada de palmeras. El templo y el colegio-residencia formaban uno de los lados de la plaza y su sistema constructivo se iniciaba por la cubierta, ya que las lluvias y humedad no permitían el empleo de adobe, paja y barro directamente.

Menos de un siglo permanecieron los religiosos jesuitas en tierras chiquitanas, ya que en 1767, todos los misioneros fueron expulsados de España y sus dominios por orden del rey Carlos III. Las misiones continuaron en el sistema reduccional a cargo del Clero Diocesano 
de Santa Cruz durante 163 años, hasta que en 1930, los franciscanos se hicieron cargo, creando el Vicariato Apostólico de Chiquitos. Posteriormente, este Vicariato da lugar a dos territorios eclesiásticos; así, en la actualidad la Chiquitania cuenta con el Vicariato Apostólico de Ñuflo de Chávez y la Diócesis de San Ignacio de Velasco.

Las reducciones se mantuvieron aisladas hasta el último tercio del siglo XIX, cuando sus pobladores empezaron a mestizarse. Fue el aislamiento el que libró a los chiquitanos de perder su originalidad cultural.

La mayoría de las ex misiones de Chiquitos, en palabras de Coimbra, continúan «vivas», expresadas en templos, partituras originales de música barroca, y tallas en madera, plata y oro que encierran un gran valor iconográfico. Esto, combinado con la presencia de los indígenas chiquitanos que conservan gran parte de su cultura, como determinadas danzas, son las razones que llevaron a la UNESCO a declarar, a este conjunto misional, como Patrimonio Cultural de la Humanidad en 1990.

\section{La cooperación internacional del Ministerio de Trabajo, Migraciones y Seguridad Social}

El Ministerio de Trabajo, Migraciones y Seguridad Social programa anualmente una serie de asistencias técnicas de cooperación internacional. La gran mayoría de ellas tienen como destinatarios a países de Iberoamérica. Estas asistencias versan sobre las diferentes materias propias de las competencias de este ministerio, tales como fomento de empleo, prevención de riesgos laborales, formación, inspección de trabajo, relaciones laborales, ... y, entre ellas, economía social. Para la ejecución de estas asistencias técnicas, el ministerio designa expertos en las diferentes materias, elegidos entre empleados públicos y cuentan con la colaboración en destino de las Consejerías de Trabajo, Migraciones y Seguridad Social de las Embajadas de España, allá donde se cuenta con la presencia de estas consejerías; y, de la Agencia Española de Cooperación Internacional al Desarrollo (AECID).

En la programación de 2018, se incluyó una asistencia técnica con el objetivo de elaborar un manual de metodología de implementación de la visión de la economía social en los talleres productivos de la Escuela Taller de la Chiquitania. La función principal de esta asistencia sería la redacción del referido manual, tras realizar el análisis correspondiente de la región y el diagnóstico sociolaboral de la misma, de forma conjunta con los monitores de la ETCH. La parte general del manual se aplicará en las diferentes escuelas taller de Bolivia en los distintos pro- 
cesos formativos y actividades laborales que se llevan a cabo y otras que se puedan desarrollar en el futuro.

Las funciones encomendadas a esta asistencia técnica, además de elaborar el referido manual, son las siguientes:

- Toma de contacto e identificación del entorno y la realidad de la región.

- Implementar políticas activas de empleo y de reconversión laboral en poblaciones que están dedicadas a actividades económicas que no cumplan con la política de trabajo decente.

- Fomentar emprendimientos asociativos e implementación de esquemas de economía solidaria en zonas rurales dispersas y en zonas postconflicto. Introducir nuevos conceptos de trabajo del tercer sector a la institución y a los estudiantes.

- Apoyar en la implementación de la metodología en los dos talleres productivos puestos en marcha en la actualidad (gastronomía y carpintería) y en la aplicación del modelo piloto en los estos talleres productivos.

- Realizar talleres participativos con egresados y actuales alumnos para socializar los conceptos y la metodología a ser implementada posteriormente en el manual.

La ejecución de esta asistencia técnica y el acercamiento a la realidad de la Chiquitania, para desarrollar la misma, han hecho posible la redacción del presente artículo.

\section{La Escuela Taller de la Chiquitania}

Las escuelas taller constituyen un programa público de empleo-formación que tiene como finalidad la inserción de desempleados jóvenes, a través de su cualificación en alternancia con la práctica profesional, en ocupaciones relacionadas con la recuperación o promoción del patrimonio artístico, histórico, cultural o natural, así como con la rehabilitación de entornos urbanos o del medio ambiente, la mejora de las condiciones de vida de las ciudades, así como cualquier otra actividad de utilidad pública o de interés general y social que permita la inserción a través de la profesionalización y experiencia de los participantes.

El origen de este programa formativo puede situarse en España en 1985. Se gestó la idea de crear las escuelas taller como plataformas de formación teórico-práctica para alumnos de entre 16 y 25 años. Como primer fruto, se empezó a rehabilitar el Monasterio de Santa María la Real, en Aguilar de Campoo. 
La cooperación española puso en marcha, en 1984, el Programa de Preservación del Patrimonio Cultural de Iberoamérica. Esta intervención se centra en la recuperación urbana y la reactivación funcional de los centros históricos de las ciudades iberoamericanas. Su desarrollo se ha estructurado en torno a tres líneas de actuación complementarias, como son la revitalización de centros históricos, la restauración de monumentos y la promoción de escuelas taller. Este último programa se inició en Iberoamérica en 1991, como apoyo a la realización de obras de restauración concretas, mediante la creación de centros de formación, concebidos bajo criterios metodológicos de formación-acción.

El proyecto de la Escuela Taller de la Chiquitania (ETCH) forma parte de la Asociación Civil Plan Misiones. Tiene como objetivo principal consolidar la formación ocupacional en oficios y especialidades vinculadas a la gestión del patrimonio cultural chiquitano. Se pretende su revalorización, contribuir a su mantenimiento; y, siempre, con vinculación al mercado; y, por lo tanto, supone un compromiso para intentar la mejora de la calidad de vida.

La ETCH es una instancia de generación de conocimiento, en la que se apuesta por la calidad y la especialización en lo local. Esto se complementa con la investigación y la recuperación técnica. Así, se realizan propuestas innovadoras con bases sólidas, tanto en lo social, como en la investigación, o en los modelos de negocio para el fortalecimiento y su aporte al desarrollo local.

La ETCH nació el año 2007, como un proyecto del Plan Misiones, adscrita a la obra de rehabilitación integral del Conjunto Misional de San José de Chiquitos. Como puede apreciarse, el patrimonio histórico está en el origen del proyecto.

Participan en el proyecto de la Escuela Taller, los integrantes del Plan Misiones; el Gobierno Autónomo Departamental de Santa Cruz, los municipios de San Rafael, San Miguel, San Ignacio, San José, Roboré San Xavier, Concepción y San Antonio de Lomerío, la Diócesis de San Ignacio de Velasco, el Vicariato Nuflo de Chávez, la Agencia Española de Cooperación Internacional al Desarrollo (AECID). Además, el proyecto ha recibido apoyo de la Corporación Andina de Fomento (CAF), la Cooperación Canadiense a través de CUSO, la Fundación W. P. Schmitz, PRO Bolivia, la Cámara de Exportadores, Logística y Promoción de Inversiones de Santa Cruz (Cadex), el Centro de Promoción Agropecuaria Campesina (CEPAC), Centro para la Participación y el Desarrollo Humano Sostenible (CEPAD), entre otros.

Desde el 2012, se cuenta con el reconocimiento de las especialidades de las escuelas taller de Bolivia como parte del sistema educativo, 
reconociendo los niveles de certificación y los currículos de las especialidades.

La formación basada en la filosofía de aprender - haciendo, hoy generalizada en muchos otros institutos del país, permite que los jóvenes adquieran habilidades y destrezas con una fuerte carga práctica, aproximadamente un $80 \%$, frente a un $20 \%$ de teoría. (En la actualidad, se está muy cerca de esos parámetros, pero no llega a cumplirse estrictamente).

Esta forma de actuar ha permitido la intervención en una gran cantidad de obras, destacando los seis conjuntos misionales nominados Patrimonio de la Humanidad: San José de Chiquitos, San Rafael, San Miguel, Concepción, San Xavier y Santa Ana y en el parque nacional Santa Cruz la Vieja, lugar fundacional de Santa Cruz de la Sierra, específicamente en el sitio arqueológico. Además, se incide en la mejora de la imagen urbana. Para ello, se realizan, entre otras, actuaciones en plazas, fachadas de edificios, señalizaciones y obras de carácter social.

La ETCH hasta ahora ha formado estudiantes en los siguientes oficios y especialidades: albañilería para la restauración, arqueología, artesanía tradicional, bienes muebles, carpintería para la restauración, instalaciones eléctricas e hidrosanitarias, gastronomía chiquitina (gastronomía y alimentación), jardinería y paisajismo, metales y servicios turísticos (turismo).

En los últimos años, se ha trabajado en una nueva estrategia de sostenibilidad Institucional y económica que puedan asegurar, en el futuro, las acciones propuestas para la gestión cultural del patrimonio chiquitano, tanto del proyecto ETCH, como del Plan Misiones. En este contexto, se inicia, a partir del 2017, un nuevo ciclo de la ETCH, desarrollando temas de innovación en los procesos, desconcentrando los talleres en el territorio y creando dos talleres productivos para la generación de recursos propios y de oportunidades de trabajo a graduados de la escuela. Estos dos talleres son de carpintería y de gastronomía. Este segundo taller ha supuesto la apertura de un restaurante en la sede principal de la ETCH en San José. El objetivo de este nuevo ciclo es buscar una sostenibilidad técnica, económica e institucional del proyecto en la región.

\subsection{Análisis de la situación de la ETCH}

Lo primero que se observa, al entrar en contacto con la ETCH, es la constatación de que el personal que presta servicios en esta se encuentra muy identificado con el proyecto. Se dedican a ello con gran tesón y esfuerzo. Es habitual observar como realizan funciones que exceden de 
su trabajo en las relaciones con los estudiantes, a los que se dan consejos, información, asesoramiento; e, incluso, se les proporcionan opciones de pequeños trabajos. Estas actuaciones van más allá de las obligaciones propias de su tarea, pero las realizan mostrando el alto grado de su compromiso con el proyecto.

La participación de profesionales conocedores del oficio y de las condiciones reales de trabajo en la actividad, como destaca Amor Bravo ${ }^{9}$, es uno de los aspectos que suponen un éxito para los objetivos del programa y está en el origen de su capacidad para garantizar la inserción laboral de los alumnos y el conocimiento de las técnicas. Afirma que los monitores no solo facilitan a los jóvenes una orientación profesional acorde con su conocimiento de la realidad del mercado, sino que, en muchos casos, les sirven como referencias en la búsqueda del empleo, actuando como eficaces agentes de inserción laboral de los jóvenes alumnos. Aspecto que, como decimos, se cumple a la perfección en la ETCH.

Su participación en el proyecto de la asistencia técnica, consistente, como ya hemos dicho, en elaborar un manual de metodología para implementar la visión de la economía social en los talleres productivos de esta escuela taller ha sido muy valiosa. Han aportado mucha información relevante, han facilitado interesantes contactos y han contribuido a que los alumnos comiencen esta nueva andadura, donde, con carácter general, han oído hablar por primera vez del término y concepto de economía social. Los monitores se han identificado perfectamente con este concepto y han asumido el compromiso de ofrecer las nociones básicas en la materia a todos los alumnos de la ETCH, además, de animar a estos para que valoren la posibilidad de constituir empresas de este tipo.

Podemos apreciar, sin lugar a dudas, que el personal con el que cuenta la ETCH es insuficiente. Cada experto que pasa por el centro, para prestar una asistencia técnica, prescribe que se debe incluir en el itinerario formativo un módulo o una visión de su especialidad (prevención de riesgos laborales, sostenibilidad medioambiental, orientación laboral, igualdad, economía social,...). Resulta materialmente imposible que los monitores existentes en la actualidad abarquen todas esas materias y las impartan a los alumnos con garantías de éxito. Necesitan apoyo de monitores, no tanto de oficios, ya que ellos los dominan perfectamente, sino de todas estas actividades complementarias; pero, necesarias para una formación integral de los estudiantes y para mejorar sus opciones de empleo decente y de calidad.

9 AMOR BRAVO, E. «Veinte años del programa de escuelas taller, casas de oficios y taller de empleo (reflexiones para el futuro)». Revista Trabajo y Asuntos Sociales, n. 71.2008, págs. 123-148. 
Los alumnos egresados con los que ha habido contacto, los participantes en los talleres productivos y los alumnos próximos a graduarse, con los que se han realizado algunas actividades durante el desarrollo de la asistencia técnica, han manifestado un alto grado de satisfacción con su paso por la ETCH y con la formación recibida. Además, todos ven como una opción a tener en cuenta, para su futuro profesional, la posibilidad de constituir pequeñas empresas participativas, autogestionadas de forma democrática, con compañeros de formación. Este posicionamiento resulta positivo para la implementación de la visión de la economía social en la formación de los alumnos y de los participantes en los talleres productivos. Esta actitud debe ser aprovechada por la ETCH para proponer la creación de pequeñas empresas participativas constituidas por personas formadas en la misma.

Como resumen, podemos concluir lo siguiente:

- Ha quedado demostrada la eficacia de la ETCH en materia de formación de recursos humanos cualificados en oficios vinculados a la preservación y restauración del patrimonio cultural y la gastronomía. Esta calidad formativa se refleja en el patrimonio rehabilitado.

- Se ha contribuido significativamente a la mejora de la empleabilidad de los jóvenes participantes en el proyecto. Se consiguen altos niveles de inserción laboral relacionada con la formación recibida. No obstante, sería conveniente dotar a la ETCH de mecanismos específicos de apoyo a la inserción, de orientación laboral y de seguimiento del proceso de inserción, con el objetivo de facilitar el acceso al mercado de trabajo o a la creación de proyectos emprendedores por parte de los alumnos egresados.

- Como impacto de esta actividad en la sociedad, cabe destacar la mejora de la formación profesional en general, de las condiciones de empleabilidad de las personas formadas, así como de la valoración social de los oficios asociados a la conservación del patrimonio histórico-artístico y cultural.

\subsection{Actividades económicas que se pueden realizar en los talleres} productivos de la ETCH e ideas de posibles emprendimientos de economía social

Los talleres productivos se han configurado para conseguir, por un lado, un mayor grado de especialización de los alumnos egresados, realizando trabajos para terceros bajo la supervisión y tutela de la ETCH; y, 
por otro lado, como mecanismo que contribuya a la sostenibilidad del proyecto, al obtener unos recursos que permitan afrontar nuevas especialidades formativas en la ETCH, que, a su vez, puedan satisfacer nuevas necesidades detectadas en la región.

De las entrevistas mantenidas con los representantes del Plan Misiones, con los responsables y trabajadores de la ETCH, con alumnos egresados de la escuela taller y de los que están próximos a la graduación, así como del recorrido por las localidades que albergan conjuntos misionales y otras que no cuentan con este recurso turístico, se han detectado diversas actividades que pueden ser realizadas por los talleres productivos enclavados en el seno de la escuela taller y constituir el germen de microempresas de economía social constituidas por alumnos formados en la ETCH. Se señalan las siguientes:

\subsubsection{GASTRONOMÍA}

El tipo de turista que pretende disfrutar del patrimonio artístico, histórico, cultural o natural; también busca, habitualmente, otro elemento de la tradición de la zona que visita, cual es la gastronomía local. Se interesan por los platos tradicionales preparados a base de productos de la tierra. Se debe trabajar, como ya se hace en la ETCH, para que sean menús sanos y equilibrados y recuperar lo más tradicional de la gastronomía local. Hay que intensificar la política de control de calidad, para garantizar esas características en los platos ofertados. No podemos olvidar que la especialidad que se imparte no solo se refiere a la gastronomía, sino también a la alimentación, por lo que los elementos nutricionales; y, no solo los culinarios, están presentes en todas las actuaciones de la escuela taller en esta materia.

La actividad de gastronomía puede ir acompañada del ofrecimiento de otros productos y actividades que demanda el visitante y la ciudadanía de la zona, Así, podemos referir diversas actividades que tendrían encaje en el área de gastronomía:

- Restaurante en la ETCH. Ya existe. Puede dar servicio de comidas en el mismo y realizar eventos dentro y fuera del recinto de la escuela taller. Se deben ofrecer menús con las características que referíamos anteriormente. Se puede ofertar el servicio de almuerzo a personas que presten su actividad profesional en instituciones públicas o privadas vinculadas de alguna manera a la ETCH (los denominados pensionados, en la terminología utilizada en la zona). El restaurante ya está ofreciendo todos los domingos un menú familiar, como se denomina habitualmente en la región. 
- Productos horneados. Elaboración de los mismos y venta directa a particulares y a establecimientos. Estos productos también se deberían servir en los cafés que se pueden establecer en los diferentes conjuntos misionales. Para ello, sería conveniente crear una marca específica y reconocible como representativa de una calidad de alto nivel. Estos productos tienen una gran demanda y se pueden encontrar en muchos lugares; pero, los ofrecidos por la ETCH son de una calidad contrastada. Ya hay un proyecto en el ámbito de horneados en marcha, en el que se están produciendo pan casero, empanada de queso al horno, cuñapé y pan de arroz.

- Servicio gastronómico a domicilio. Se pueden servir menús tradicionales y con claro valor nutricional. Conviene explorar la posibilidad de introducir menús vegetarianos, no habituales en la zona y de ofrecer un servicio de elaboración y reparto de desayunos a domicilio, ofreciendo opciones de desayunos típicos y saludables.

- Elaboración de productos envasados, tales como mermeladas, conservas, compotas o salsas. Sería una buena opción para aprovechar diferentes productos de alta calidad de la zona que, a veces, no hay tiempo suficiente para consumirlos en fresco en su totalidad y evitar, de esta manera, que se desperdicien. Se deberán de utilizar, siempre que sea posible, conservantes naturales. Estos productos, también, tendrían que ser amparados por una marca reconocible, que se identifique como sinónimo de calidad.

- Aprovechar los productos de temporada de la región. Muchos visitantes se interesan por conocer estos y que platos les pueden ofrecer con los mismos. Vale la pena realizar el esfuerzo de configurar imaginativos menús con estos productos específicos no disponibles todo el año.

\subsubsection{CARPINTERÍA}

El respeto por el medio ambiente debe de ser una de las señas de identidad de esta actividad, unida al aprovechamiento de las maderas producidas en la zona. Como vemos, el respeto por el entorno y la utilización de los recursos y materias primas más próximas siguen siendo notas dominantes de las actividades propuestas. Las que se apuntan desde el taller productivo de carpintería para posibles futuras microempresas de economía social, son las siguientes: 
- Para la construcción, se realiza fabricación de puertas, ventanas, ... y su instalación. Esta actividad es conocida y habitual en el taller productivo actual.

- Fabricación de mobiliario doméstico o para actividades profesionales, tales como mesas, sillas,... Se elaborarán diferentes prototipos para ofertar a posibles clientes, evitando stocks de productos caros y de no excesiva demanda.

- Fabricación de productos tradicionales de forma artesanal, por ejemplo, utensilios de cocina y recuerdos típicos en madera de la visita turística a la Chiquitania.

- Se recomienda valorar la posibilidad de ofrecer demostraciones de la realización de trabajos artesanales de madera a los visitantes de la ETCH, lo que puede servir de reclamo para la adquisición de esos productos.

\subsubsection{CONSTRUCCIÓN}

Para los alumnos formados en albañilería existen oportunidades de realizar trabajos en el mantenimiento y pequeñas reformas de las viviendas construidas con las técnicas tradicionales de la zona. Este tipo de construcción presenta una buena opción para los alumnos egresados de la escuela taller. Se utilizan los recursos propios de la zona, respetando los materiales nobles, no utilizando cemento o hierro, sino tierra, paja, tabique o madera rolliza de monte, lo que contribuye al rescate de las técnicas tradicionales y respetuosas con el medio ambiente.

Pero, para dar más contenido a este sector, se proponen diversas actividades que pueden contribuir a la sostenibilidad del sistema actual:

- Aprovechar la experiencia en la restauración de bienes del patrimonio histórico - cultural que tienen los alumnos egresados de la ETCH para abrir la posibilidad de realizar la rehabilitación y restauración de diferentes construcciones públicas y privadas. Se puede ofrecer este servicio a las correspondientes autoridades encargadas de gestionar el mantenimiento de colegios, centros médicos, instalaciones municipales,... para que se afronten las necesidades de rehabilitación por estos trabajadores que han demostrado su valía con la restauración de elementos muy delicados, que tienen, incluso, el reconocimiento como patrimonio de la humanidad. Para lograr el acceso a estas obras y cumplir este objetivo, se considera muy importante la implicación del Plan Misiones, sobre todo, por las instituciones que participan de su estructura. 
— Elaboración de bloques prefabricados de hormigón para cámaras fluviales, desagües,...

- Fabricación de elementos ornamentales decorativos, tales como molduras, cornisas o rosetones.

- Fabricación de adobes. Se trata de un elemento muy demandado en la construcción en la zona. Resulta de fácil elaboración y tiene muchas opciones de comercialización en la región.

\subsubsection{ACTIVIDADES DE CARÁCTER GENERAL}

De la visita a los diferentes conjuntos misionales y a las localidades donde estos se encuentran, se aprecia la posibilidad de realizar nuevas actividades que se consideran necesarias y que no se ofrecen en la actualidad. Estas, entendemos que pueden realizarse con los alumnos egresados de la ETCH y los proyectos empresariales de economía social propuestos, para ello, podrían ser auspiciados por el Plan Misiones y la propia escuela taller.

- Se puede contemplar la posibilidad de crear un equipo permanente de trabajadores que realicen de forma itinerante los trabajos de mantenimiento y restauración de los diferentes conjuntos misionales. Dedicarían el tiempo necesario a cada conjunto; pero garantizando el paso anual por cada uno de ellos. El equipo sería permanente, pero no localizando su trabajo en un único lugar. Se evitaría el deterioro de los monumentos y que se realicen trabajos de mantenimiento o restauración por personas no conocedoras de las técnicas apropiadas para este tipo de trabajo.

- En los conjuntos misionales, se pueden crear equipos de trabajo para atención a los visitantes. No nos referimos a guías turísticos, sino a personas que presten su apoyo a los visitantes que tengan problemas de movilidad, o necesiten alguna atención especial. Ofrecerían, además, información sobre los recursos de la zona y realizarían labores diversas de asistencia a las personas que precisen de su concurso.

- Establecer puntos de información turística, para suministrar datos básicos sobre ubicación de hoteles o restaurantes, de posibles visitas a realizar por la zona partiendo de ese punto de información,...

- Señalización de las vías de acceso a los diferentes recursos turísticos. Es una labor sencilla y que facilitaría el tránsito de las personas que visitan los conjuntos misionales. Se aprecia una falta considerable de señalización de los diferentes puntos de interés. 


\subsection{Vías de comercialización de los productos}

No es suficiente con tener una amplia oferta de productos y servicios. Es necesario que toda esa oferta sea conocida para poder entrar con fuerza en los circuitos comerciales. Puede haber fórmulas generales para dar a conocer todo lo que el entorno de la ETCH ofrece; $y$, otras serán específicas para algún producto o servicio o un conjunto de ellos. Apuntamos, como posibles, las siguientes vías:

- La propia ETCH. Esta debe ser un escaparate físico de toda la oferta. Los prototipos de muebles, las artesanías de madera o los productos alimenticios para llevar deben estar visibles y disponibles para su adquisición en el mismo centro. Los productos que, por su volumen $u$ otras circunstancias no puedan mostrarse físicamente deberían de estar accesibles para su visionado mediante fotografías, catálogos,...

- Vía internet y redes sociales. Se debe garantizar, por esta vía, que todos los productos y servicios pueden ser consultados. Deberá informarse si los productos están disponibles, si se producen bajo pedido, plazos de entrega y forma de llevar a cabo esta y cualquier otra información de relevancia sobre cada producto o servicio ofertado.

- Presencia en ferias. Los productos artesanales de madera y gastronómicos deben estar presentes en las ferias que se celebren en toda la región. Un único stand de la ETCH debe aglutinar toda la oferta posible, aunque sea dispar entre sí. Además, se debe publicitar la existencia de otros productos y servicios que no se exponen allí. Es decir, igual que en sede de la ETCH todo debe estar presente, aunque sea a través de catálogos.

- Establecer contactos con agencias de viaje. A los grupos organizados que visitan el conjunto misional de San José de Chiquitos hay que ofrecerles la posibilidad de almorzar en el restaurante del centro.

- Cartelería. En los trabajos que se realicen de albañilería, pintura o instalaciones de elementos de madera por parte de la ETCH se deben poner carteles bien visibles que informen de que el trabajo se lleva a cabo por esta institución. Cualquier persona, que vea el trabajo, puede mostrar su interés por encargar alguna labor similar.

- Fijar técnicas de fidelización de clientes. Sería conveniente que a los clientes, sobre todo del área de gastronomía, se les regalara algún producto de bajo coste por su compra, se le concedieran 
descuentos para compras próximas, consumiciones gratuitas al superar un número mínimo de adquisiciones,... Con estas promociones se busca que el grado de fidelización del cliente sea el más alto posible, al menos, en la etapa inicial del proyecto.

\section{De los talleres productivos de la ETCH a microempresas de economía social}

Como decíamos anteriormente, la ETCH ha dado un importante paso adelante para conseguir realizar actividades productivas con los alumnos que han finalizado el periodo de formación; pero, que no tienen la suficiente experiencia para trabajar de forma totalmente autónoma. Estas actividades generan recursos para la ETCH y oportunidades de negocio al contactar con diferentes clientes que demandan los productos de estos talleres.

Ahora se plantea dar un paso más. Se pretende que esos talleres productivos; $y$, la experiencia acumulada en los mismos, se puedan aprovechar por los alumnos egresados de la ETCH; y, que han perfeccionado sus conocimientos y experiencia profesional en los talleres, para establecer microempresas de base asociativa entre ellos. Ya se están realizando actividades como las referidas anteriormente del restaurante o los horneados, así como alguna actividad en el área de construcción. Para dar este paso, se considera necesaria una labor de acompañamiento y tutorización temporal por parte de la ETCH. Los contactos que mantiene esta pueden facilitar el acceso a la adquisición de materias primas, a captar clientes, a labores de asesoramiento técnico, financiero,... pero, en cualquier caso, este compromiso de acompañamiento debe tener un periodo máximo fijado por la ETCH, pasado el cual la microempresa deberá estar en condiciones de enfrentarse por sí sola al mercado; y, así la ETCH podrá tener abierta la posibilidad de realizar esa labor de acompañamiento a otros grupos emprendedores surgidos, posteriormente, de los talleres productivos.

Los compromisos que asumen ambas partes en ese periodo de colaboración deberán ser plasmados documentalmente, para que haya claridad sobre las obligaciones y derechos de ambos y las medidas a adoptar en caso de incumplimiento.

La forma jurídica que adopten las microempresas surgidas de este proceso deberá ser una forma compatible con los principios y valores propios de la economía social. Dado que la Ley General de Cooperativas exige un mínimo de diez asociadas y asociados para poder constituir y mantener legalmente una cooperativa, se considera poco realista pen- 
sar que alguno de los emprendimientos que puedan surgir del entorno de la ETCH puedan llegar a ese número mínimo inicial de personas asociadas. Por otro lado, los posibles participantes en los proyectos emprendedores no perciben, en el entorno, la existencia de cooperativas de producción. Esto hace difícil que en proyectos de empresas de producción de nueva creación puedan optar por la forma jurídica de sociedad cooperativa. No obstante, nada impide; $y$, resulta incluso atrayente y positivo, que esos proyectos incipientes, aunque no tengan la forma jurídica de cooperativa, se organicen y gestionen como tales. Así cualquier asociación de personas para realizar una actividad económica puede gestionarse de forma democrática y no constituyendo la aportación al capital el elemento determinante de los retornos que obtengan los asociados y asociadas, sino el trabajo puesto en común. Además, deberán tener un compromiso con su entorno local, con la sociedad en general, con la igualdad de oportunidades y con el medio ambiente. Es decir, serán empresas con la forma que corresponda legalmente; pero, con espíritu cooperativo. Todas estas exigencias deberían reflejarse expresa y claramente en los estatutos de las empresas que se puedan crear.

En este sentido, entendemos que cualquier empresa que se organice y gestione de acuerdo con los principios que son inherentes a la economía social, forma parte de esta, con independencia de la forma jurídica que adopten. Por este motivo, en el manual que se ha elaborado en la asistencia técnica se ha incluido, a título de ejemplo, la normativa boliviana reguladora de las sociedades civiles y un modelo orientativo de estatutos de esa figura, con la finalidad de facilitar la creación de estos emprendimientos asociativos.

\section{Bibliografía}

Amor Bravo, E. «Veinte años del programa de escuelas taller, casas de oficios y taller de empleo (reflexiones para el futuro)». Revista Trabajo y Asuntos Sociales, n. 71. 2008, págs. 123-148.

CoImBRA, G. «Desarrollo humano sostenible en las misiones jesuíticas de Chiquitos, Bolivia: el caso del municipio de Concepción». Disponible en: http:// bioculturaldiversityandterritory.org/documenti25_300000176_08_desarrollohumanosostenible.pdf.

CORAGGIO, J.L. "La presencia de la economía social y solidaria y su institucionalización en América Latina», Documento ocasional 7. Potencial y límites de la economía social y solidaria. 2014. United Nations Research Institute for Social Development.

EVIA, J.L, JEMIO, L.C. «Informe de Milenio sobre la economía de Bolivia». Fundación Milenio. 2018, número 40. 
HillenKAmp, I. «la economía solidaria en Bolivia. Entre mercado y democracia». (c)cides-umsa/ird. 2014.

MeRCADO, A.F. «Un acercamiento a la realidad (Bolivia). En «La economía social en Iberoamérica, vol. 2, Un acercamiento a la realidad», Coordinada por Pérez Uralde, J,M, y Rodrigán Rubio, M. Fundación Iberoamericana de la Economía Social. 2002, págs. 13-41.

WANDERLEY, F. «La economía solidaria y comunitaria en Bolivia». Revista de la Academia. Volumen 21. Otoño de 2016, págs. 57-75. 